\title{
Is a village a village if no one lives there? Negotiated histories on Mabuyag in the Western Torres Strait
}

\author{
Duncan Wright ${ }^{1}$ and the Goemulgaw Kod \\ 1. School of Geography and Environmental Science, Monash University, Australia
}

\section{Introduction}

Partnership (or community) archaeology has become increasingly prominent in the Australia/ Pacific region (see Marshall 2002 and McNiven and Russell 2005). A community-led approach acknowledges the importance of indigenous control of the cultural-heritage process. This is designed to enable indigenous communities to 'maintain or establish community pride, cohesion and identity', as well as creating a 'more nuanced and textured view of the past' (Smith 1999; Nicholas 2000; McNiven and Russell 2005:244; Smith and Wobst 2005).

Divergent 'symbolic and metaphoric strategies' in oral history and archaeology are likely to result in the creation of different histories (McNiven and Russell 2005:248). This may be further influenced by methodological constraints (e.g. the validity, accuracy and representativeness of oral/archaeological histories) or the reluctance of communities to divulge secrets about their sites and practices (Sand 2000:68; McNiven and Russell 2005:48). When archaeological and ethnographic results do not correspond it is important to avoid both selective criticism of oral histories and censoring of instances where archaeology conflicts with oral accounts (Allen 1983:8; Echo-Hawk 1997; McNiven and Russell 2005:256). Partnership archaeology recognises that the cultural-heritage process requires ongoing negotiation between indigenous and archaeological communities, and in some cases the alteration of existing indigenous and/or non-indigenous cosmologies and methodologies (Nicholas 2000; McNiven and Russell 2005:248; Smith and Wobst 2005).

In 2001, a community project was initiated in the western Torres Strait to track 'archaeological signatures of ethnographically documented cultural practices back from a recent to a more distant past' (David and McNiven 2004:203). As well as providing significant information on key points of cultural change, it has also provided a case study about community-based archaeology and the methods used to explore prehistoric sites and cultural material (e.g. McNiven and Feldman 2003; David et al. 2004; McNiven et al. 2009). This paper stems from doctoral 


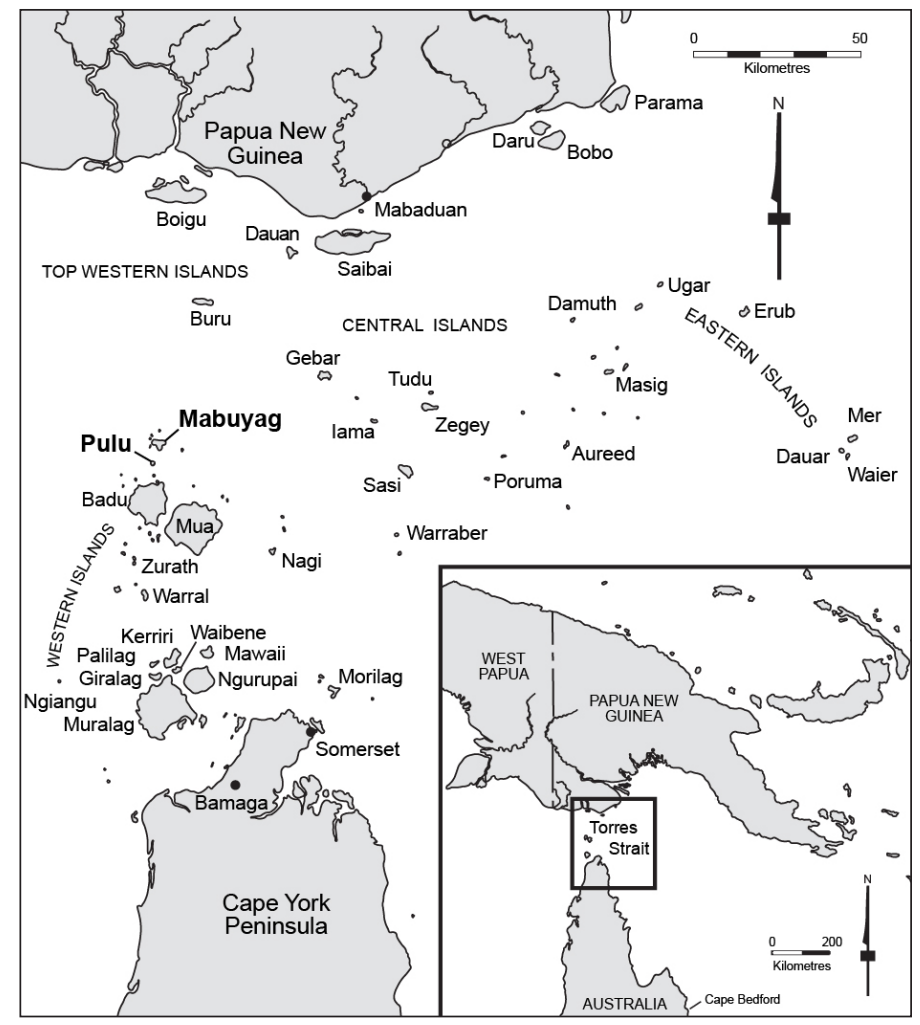

Figure 1. Map of Torres Strait Islands showing regional groupings.

research conducted during the Western Torres Strait cultural history project. It negotiates the competing histories for two ethnographically prominent 'villages', Wagadagam and Maidh, on Mabuyag in the central western Torres Strait (Figure 1).

\section{Archaeology of villages in the Torres Strait}

Two methods have been proposed to interrogate the notion of 'village' in the Torres Strait. The first conceives these sites to be 'semi-permanent to permanent places of residence containing groups of houses' (David and Ash 2008:428; see also McNiven et al. 2004:88). Using extracts from diaries, books and letters written by early European voyagers, 71 such 'villages' have been identified across 20 Torres Strait islands in the Torres Strait (McNiven et al. 2004:77, 88). In the western islands these locations were frequently abandoned during the dry season or due to sickness/death (Haddon 1890:353; Moore 1984:26), and similar practices are noted on a number of islands in the southwestern and central Torres Strait (Jukes 1847:155, 294; Thompson cited in Moore 1984:33). The term 'village' is flexible and can include occupied garden or feasting areas (McNiven et al. 2004:88; David and Ash 2008:429).

A second method of classification considers villages to be 'meaningful places connected to how people structure and understand their social spaces' (David and Ash 2008:428). This follows community histories which identify socio-political-ceremonial centres of activity relating to individual clans (cf. Haddon 1904; McNiven et al. 2004; Shnukal 2004). Such links to place continue to be firmly held by contemporary communities despite frequent relocation from traditional villages (Edmund Bani pers. com. Mabuyag 11/09/2006).

Despite the apparent disparity between these conceptions, they are not considered mutually exclusive but represent two sides (physical and metaphysical) of the village (Ghaleb 1990; McNiven et al. 2009). 
The archaeological implications of both conceptions have been broken down into a set of archaeological expectations and related methodologies. Based on the first conception, it is expected that a certain amount of spatial and temporal homogeneity will exist in the archaeological record, with villages revealing 'archaeological traces of occupation in the form of structural features (houses, fences) and occupational debris such as food remains (shell middens) and artefacts of stone, shell and bone' (McNiven et al. 2004:88; see also Harris et al. 1985; Ghaleb 1990:219-222; Barham 2000; David and Weisler 2006; McNiven 2006:9; David and Ash 2008:428; McNiven et al. 2009). The semi-permanent conception of 'village' implies that archaeologists look for evidence of residential structures or activities (e.g. post holes, house platforms, paths, hearths and earth ovens) (Fitzpatrick et al. 1998; David and Ash 2008:446447). For example, midden materials and clear activity areas (cooking, refuse) at Kurturniawak on Badu were used as evidence for village occupation despite the lack of confirming oral histories (David and Weisler 2006:21).

The second conception is harder to examine archaeologically, with villages assumed to contain both tangible (e.g. structured space, middens, paths) and intangible (e.g. story sites, trees, stones, rivers) markers (Haddon 1904:197; Shnukal 2004:323). Such sites are identified through experience and social interaction, and do not necessarily involve human modification of the landscape. In large measure, archaeologists identifying the social components of the 'village' are guided by oral and written histories (Ghaleb 1990; 1998; Ash and David 2008; McNiven and Wright 2008; McNiven et al. 2009).

\section{The ethnography of Goemulgaw villages}

Four traditional 'villages' are prominent in Goemulgaw cosmology: Wagadagam and Dabangai on the north coast of Mabuyag, and Maidh and Goemu on the east coast (Haddon 1904:266, 1935:56; Figure 2). Further smaller villages on the island include Mui and Udai (east coast), Dogai (southeast coast), Sao, Awbayth and Kodakal (north coast), Ii and Sopolai (west coast) and Dadakul and Maitan (interior) (Haddon 1904; Vanderwal 1973:178). These villages have independent totemic affiliations: the major moiety (Koey awgadhaw kazi or Koey Buway) with Wagadagam, while the minor moiety (Moegi awgadhaw kazi or Moegi Buway) is associated with most villages on the east and south side of the island (Haddon 1904:55; Eseli et al. 1998:87; Shnukal 2004:323; Adhi Cygnet Repu pers. com. Mabuyag, 12/08/2006). Villages are further divided by primary and subsidiary clan affiliation (Haddon 1904:266, 1935:56; Table 1). A further village (as well as the 'national kwod' (ceremonial men's meeting house) of the Goemulgal) is recorded for the adjacent island of Pulu (Haddon 1904:207; Lawrie 1970:85-87).

Table 1. Totemic affiliation (from sketch map drawn by Ned Waria in 1898, cited in Haddon (1904:163).

\begin{tabular}{|c|c|c|c|c|c|c|}
\hline Village & Primary totem 1 & Subsidiary totem 1 & Primary totem 2 & Subsidiary totem 2 & 2 Primary totem 3 & Subsidiary totem 3 \\
\hline Wagadagam & Crocodile & Sucker fish & Snake & Dugong & Turtle & Frigate bird, fruit bat \\
\hline Goemu & Turtle & Crocodile, dog & & & & \\
\hline Maidh & Snake & Turtle, sucker fish & & & & \\
\hline Dabangai & Dugong & Crocodile & & & & \\
\hline Pulu & Dugong & Sucker-fish & Cassowary & Dugong, snake & Dog & Turtle \\
\hline
\end{tabular}




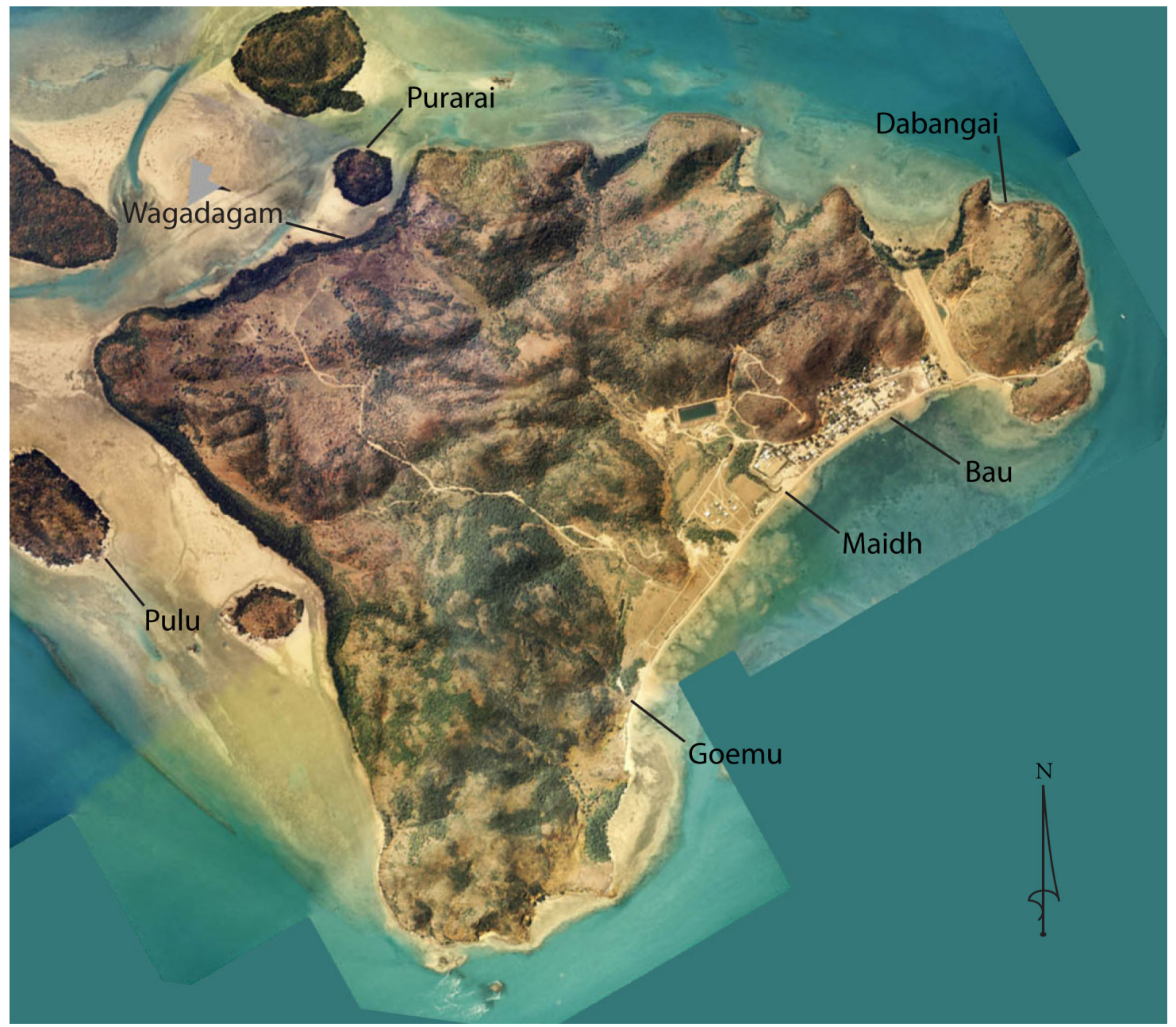

Figure 2. Map of ancestral Goemulgaw villages on Mabuyag (topographic map courtesy of Schlenker mapping; GIS by Matthew Coller). Aligned grid north.

Totemic affiliation influences the behavior and spiritual and ceremonial roles practised by the people of each village. For example, Dabangai is reputed to be the place of great dugong hunters and the location of ceremonies relating to the dugong (Haddon 1904:162, 182, 1932:76, 1935:182-183; Eseli et al. 1998:74). The people of Goemu were largely concerned with turtle fishing, and were responsible for success in turtle hunting by conducting a number of key ceremonies (Haddon 1904:164, 183, 214, 330-331, 334-345, 1935:59). The families and clans associated with each location identify the individuality of villages through tangible and intangible features (Haddon 1904:4; McNiven et al. 2009).

\section{Archaeological research at two Goemulgaw villages}

To date, archaeological research on Mabuyag has concentrated on Goemu (Barham and Harris 1987; Ghaleb 1990, 1998; McNiven and Wright 2008) and Dabangai (McNiven and Bedingfield 2008; Wright 2009). Both ethnographically prominent sites contained rich surface and sub-surface deposits, leaving little doubt of a correlation between oral history and archaeology. This research comes at the expense of two equally important Goemulgaw villages, Wagadagam and Maidh, neither of which contain substantive archaeological evidence for cultural activity (Ghaleb 1990:158). Following the partnership approach, both villages were 
chosen for archaeological research in 2006 and are examined in detail below. It is recognised that significant problems surround the reconstruction of Aboriginal boundaries and land ownership, with the publication by Sutton (1995) singled out for criticism. While this paper does not support the validity of bound social groups, it accepts that much of the material collected by Davis and Prescott (1992) parallels ethnographic material collected by Alfred Haddon (1890, 1904, 1935), Margaret Lawrie (1972) and myself.

\section{Wagadagam}

The Wagadagam region encompasses the northwest side of the island, from the forested hills inland (an area known as 'Bari') to the coastal grasslands of Wagadagam proper (Davis and Prescott 1992:118, 124). A number of adjacent islets (e.g. Woeydhul and Aipus) also appear to have been affiliated with and used by the people of Wagadagam (Haddon 1904:58, 368; Davis and Prescott 1992:124). As the divisions between regions remain contested and obscure, they are roughly illustrated in Figures 2 and 3.

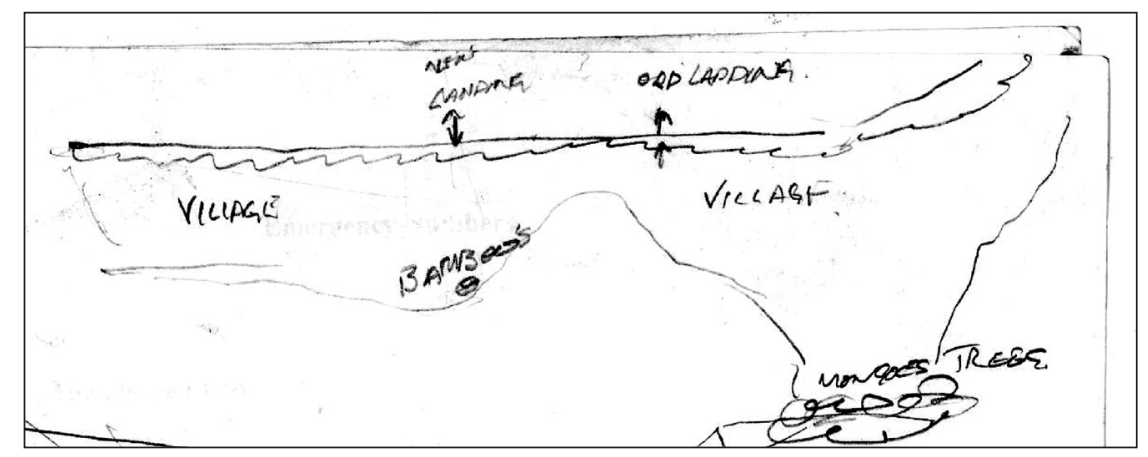

Figure 3. Sketch by Tim Gizu (of Mabuyag) of the Wagadagam village(s).

\section{Ethnography}

Lawrie $(1970: 105,108)$ suggests there were two large villages, Wagadagam and Urabal Gagait. These two locations lie adjacent to one another, with the former at the end of the current road and near the new landing place, and the latter slightly further to the west (towards Ii). Both of these villages were large enough to contain sub-districts such as Kulapis (in east Wagadagam) and Buru in Urabal Gagait (Lawrie 1970:105). An alternative arrangement recorded by Ghaleb (1990:134) was that everything from Kula pis to bur was part of the single gigantic village of Wagadagam.

Wagadagam is recorded to have been an extremely important and influential place on Mabuyag, and the focus of activities relating to the Koey awgadhaw kasi moiety, which had the koedal (crocodile) as the main totem (Haddon 1904:164, 172; Adhi Gabriel Bani pers. com. Mabuyag, 21/9/2006). At Wagadagam, decisions relating to warfare and headhunting were made by people who were 'fierce and politically minded' (Haddon 1904:185; 1935:56; Adhi Gabriel Bani pers. com. Mabuyag, 21/9/2006). According to legend, Wagadagam was also the ancestral village of the Goemulgal, with all other villages founded by the chief of Wagadagam at the time, Bari (Haddon 1904:164, 236, 267; Tabeta cited in Mooke and Simpson 1972:1; Edmund Bani pers. com. Mabuyag, 12/11/2006).

Archaeological research

Until this study, no excavations had been conducted at Wagadagam. The only conclusive evidence of former occupation was several relict mound-and-ditch fields in the northeast quarter of the 
valley, and in the same area: 'a large grove of tall bamboo growing around a water hole' (Ghaleb 1990:158; Wright 2009).

Two excavations were conducted on the Wagadagam foreshore, adjacent to the new landing place (Figure 3). As Square A had been substantially disturbed by bulldozing, this excavation was discontinued and a second $70 \mathrm{~cm}^{2}$ unit (Square B) was positioned $4 \mathrm{~m}$ away from the mangrove line on an elevated platform. With the exception of a few fragments of glass, no surface materials were observed in the locality of the excavation. Square B was excavated to a maximum depth of $63 \mathrm{~cm}$ (18 excavation units/XUs), with bedrock reached in some sections at $33 \mathrm{~cm}$ depth. There was little stratigraphic change, with sediment consistently dry and silty and mildly acidic throughout. A slight change in colouration occurs at the base of SU 1 (between $3 \mathrm{~cm}$ and $6 \mathrm{~cm}$ ) from very dark grey to black (Figure 4). This transition is reflected by a shift from consolidated, organic rich sediment to increasingly friable and unconsolidated sediment. The transition between SU 2 and SU 3 (between $27 \mathrm{~cm}$ and $30 \mathrm{~cm}$ ) was marked by substantial increases in rock, pumice and cultural materials (see Figure 4). Although the sediment is similar in texture to SU 2, it gradually reverts in colour to a very dark gray.

The main period of cultural activity at Wagadagam was dated to $800-1057$ cal. BP by three AMS dates in correct stratigraphic sequence and overlapping at two standard deviations (Table 2). Ephemeral cultural deposits continue until 5-8 cm below the ground surface, before disappearing in the top four XU. This transition was dated to 464-535 cal. BP.

Marine vertebrate bone makes up the bulk of the Wagadagam cultural assemblage (total weight $=1.4 \mathrm{~kg}$ ), with the majority of remains attributed to unidentified large vertebrates

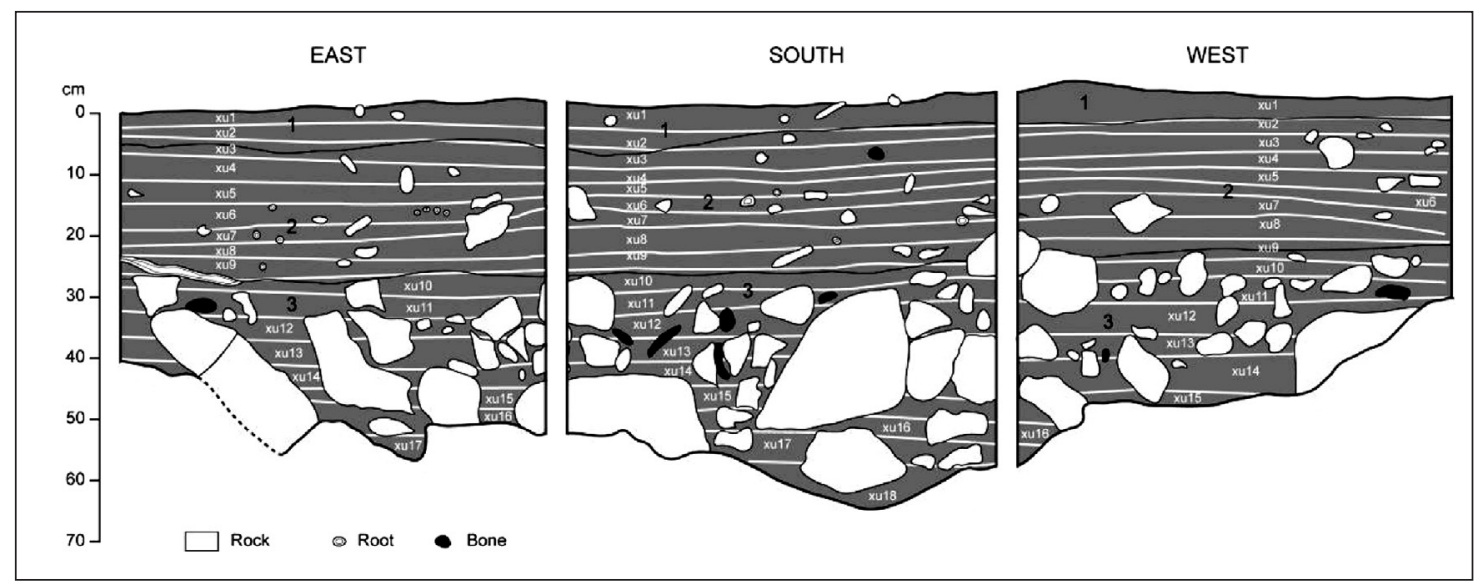

Figure 4. Section of Square B, Wag 1 showing stratigraphic units (SU 1-3).

Table 2. AMS radiocarbon dates, Square B, Wag 1. Dates in calendar years using Calib 5.0.2

\begin{tabular}{llllllll}
\hline $\begin{array}{l}\text { Laboratory } \\
\text { code }\end{array}$ & Square B: XU & $\begin{array}{l}\text { Depth below } \\
\text { surface }(\mathbf{c m})\end{array}$ & Sample type & $\begin{array}{l}\text { Sample } \\
\text { weight }(\mathbf{g})\end{array}$ & ${ }^{13} \mathbf{C}$ & ${ }^{14} \mathrm{C}$ age & $\begin{array}{l}\text { Calibrated age } \\
\text { (cal. BP) }\end{array}$ \\
\hline WK-24932 & B: 4 & $7-11$ & Charcoal & 0.43 & $25.7 \pm 0.2$ & $486 \pm 30$ & $464-535$ \\
WK-24933 & B: 10 & $30-32.5$ & Charcoal & 0.38 & $24.4 \pm 0.2$ & $1050 \pm 40$ & $896-968^{*}$ \\
WK-24934 & B: 16 & $53-56$ & Charcoal & 0.14 & $25.3 \pm 0.2$ & $1134 \pm 30$ & $\begin{array}{l}932-1018^{*} \\
16\end{array}$ \\
WK-24935 & B: 18 & $60-63$ & Charcoal & 0.5 & $25.3 \pm 0.2$ & $1140 \pm 30$ & $951-1057^{*}$ \\
& & & & & & & $934-948$ \\
\hline
\end{tabular}

Dates expressed as cal. $B P=$ before AD 1950. * ${ }^{*}$ highest probability calibrated age range. 
(88.5\%) and dugong (11\%). The remaining turtle and fish bone makes up less than $0.5 \%$ of the total. Marine vertebrate bone was present in small quantities within SU 1 (total of $55.5 \mathrm{~g}$ per 101 of deposit), increasing in SU 2 (total of $286.7 \mathrm{~g}$ per 101 of deposit). The majority of bone comes from the top of SU 3 (XU 10-15), at which stage there is total of 472.7 g per 101 of deposit. After this point, the quantity of marine vertebrate bone drops considerably (total of $26.3 \mathrm{~g}$ per $10 \mathrm{l}$ of deposit). During excavation it was noted that the transition was matched by a significant drop in bone size, suggesting some bioturbation (Figure 5).

Considerable charcoal (40.3 g) was excavated from all XUs until XU 12, with 73\% (17.0 g per 101 of deposit) recorded between XU 7 and XU 11. There is a further minor charcoal peak in the basal two XUs, although this is considered to be the result of natural bioturbation of small fragments.

Square B contains a total of 3143 flaked stone artefacts and a further three ground stone/ ochre pieces. Quartz was the prominent material used to make flaked artefacts $(n=3043)$, followed by igneous $(n=93)$ and glass $(n=7)$. The remaining non-flaked artefacts consisted of two fragments of ground ochre and a single stone implement with use impact. The bulk of artefacts (by number) comes from the upper 12 excavation units (SUs 1, 2 and the top of 3). This accounts for $96 \%$ of the quartz and $92 \%$ of the igneous flaked assemblage (Figure 6). Of the igneous flaked artefacts, the bulk come from between XU 6 and XU 12 (75\%), while the ground stone and ochre is restricted to XU 3 and XU 4. Flaked glass is restricted to the upper three XUs, roughly corresponding with the SU 1 deposit.

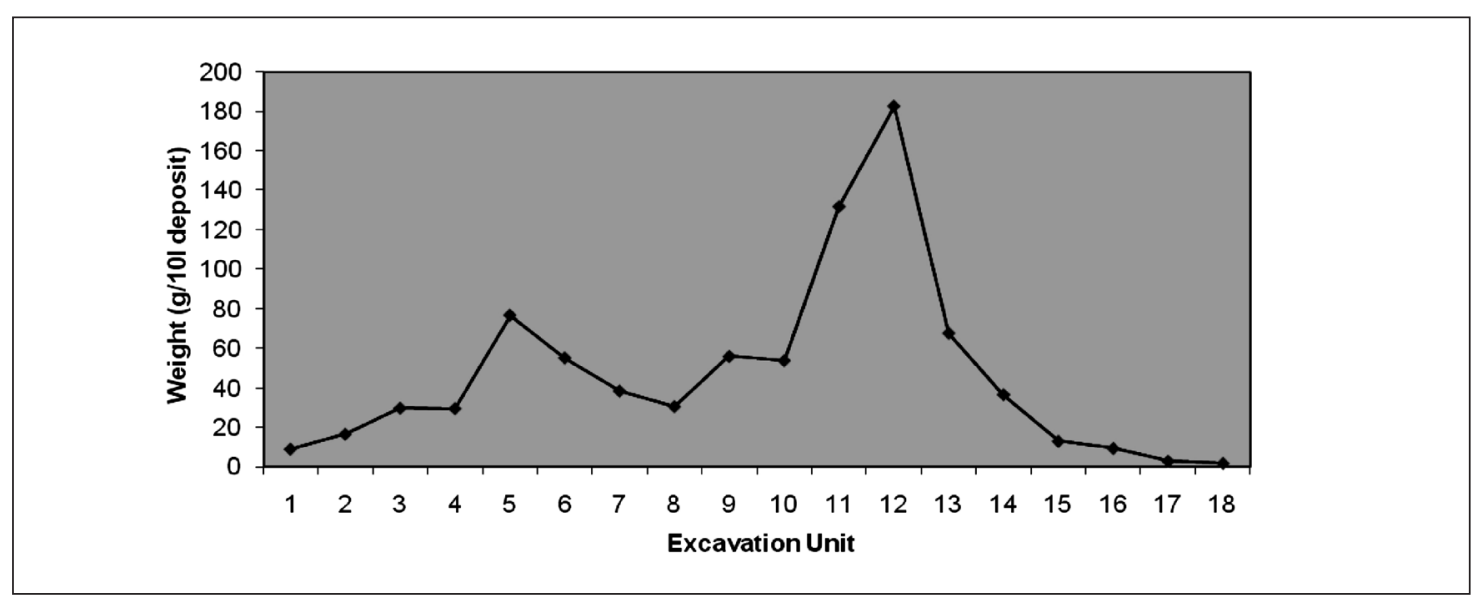

Figure 5. Vertical change in marine vertebrate bone density, Square B, Wag 1.

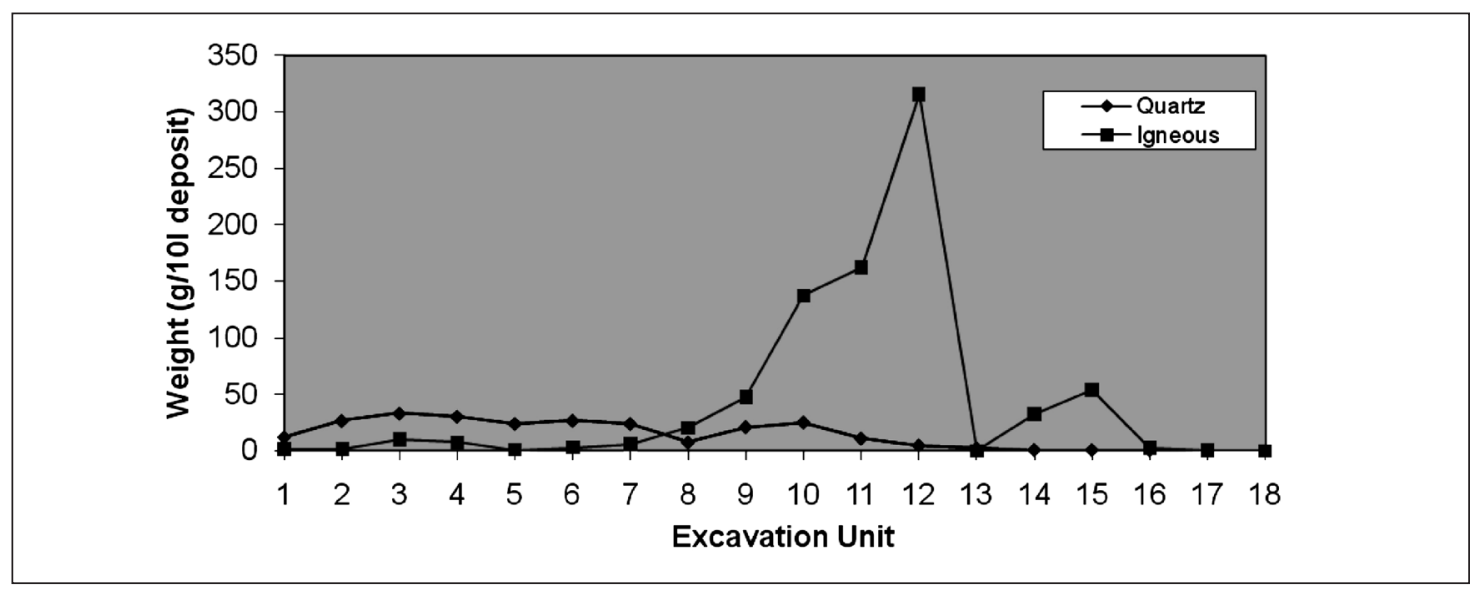

Figure 6. Vertical change in flaked stone artefact density, Square B, Wag 1. 


\section{Maidh}

Davis and Prescott (1992:127) suggest that: 'the boundary between Wagedagam and Maidh follows a ridge line, a criterion which also accords with the northern boundary between Maidh and Panai' (see Figure 2). The southeast boundary of Maidh generally follows a line excluding the beach and foreshore area, which has become the focal residential area for the Mabuiag population. Other sources suggest that Maidh includes the villages of Bau, Maidh and Mui, with all of these areas falling within the jurisdiction of thabu (snake) and koedal (crocodile) clans (Haddon 1935:56; Rivers cited in Haddon 1935:55; Aaron Whap pers. com. Mabuyag, $1 / 12 / 2006)$.

The paucity of cultural material was explained by traditional owners as evidence for the different role of Maidh within the community. This was not considered a residential place but rather an important totemic and ceremonial site (Young Bani pers. com. Mabuyag, 1/12/2006; see Haddon 1904:97, 327). The 'village' (for that is what the Goemulgal call this site) was used by the Maidhelaig (or spiritual people) to conduct ceremonies at a large house (merkai mud or 'dead man's house'), with a high, steep roof and low walls (Haddon 1890:399). The area was restricted to certain members of the community: 'if an unauthorised man or any woman entered a merkai mud they would die' (Haddon 1890:399; Adhi Dimple Bani pers. com. Mabuyag, 1/9/2006). During the early 19 th century, these restrictions appear to have been lifted, with the village increasingly used for gardening (Mooke and Simpson 1972:17; Done cited in Stevenson 1987; Eseli et al. 1998:27; Figure 7).

\section{Archaeological research}

Site surveys were made between July and October 1984 by archaeologists from University College London (Harris et al. 1985; Barham and Harris 1987). Investigations revealed few cultural surface materials or sites associated with cultural activity (Harris et al. 1985:48). The exceptions were relict fields and two stone arrangements in the shape of turtles observed on a hillside overlooking Maidh (Barham and Harris 1987:32). A survey in 2006 by the author revealed stone cairns in the Maitan valley region of Maidh. These were attributed by the Goemulgal to a recent period of land clearance for gardens (T. Gizu pers. com. Mabuyag, 8/11/2006).

Two 'test pits' were dug at an unspecified location at Maidh (Harris et al. 1985:48). The pits did not reveal any buried soil or former land surface that might have provided charcoal or other datable organic material (Harris et al. 1985:48). Due to site disturbance relating to the expansion of the modern village of Bau, further excavation of this site was not considered feasible (Wright 2009). An examination of bulldozed spoil heaps and house foundations in the eastern margins of Maidh also revealed little evidence for human settlement. The eroding creek bed which runs through the centre of Maidh did not contain any evidence of significant human activity.

\section{Discussion and conclusion}

Two villages that from the outset were expected to reveal little archaeological information about human settlement on Mabuyag were examined archaeologically. The lack of surface (and in the case of Maidh, sub-surface material) was initially conceived as evidence for contradictory histories between archaeology and ethnography. Following the partnership model, both sites were investigated to give insight into the broader cultural heritage of the indigenous communities.

The antiquity of 'villages' was expected to date to between $850 \mathrm{cal}$. BP and $550 \mathrm{cal}$. BP (cf. McNiven 2006). However, as evidenced by Mabuyag, archaeological research frequently considers the culturally rich areas (e.g. Goemu and Dabangai) as priority sites for research 


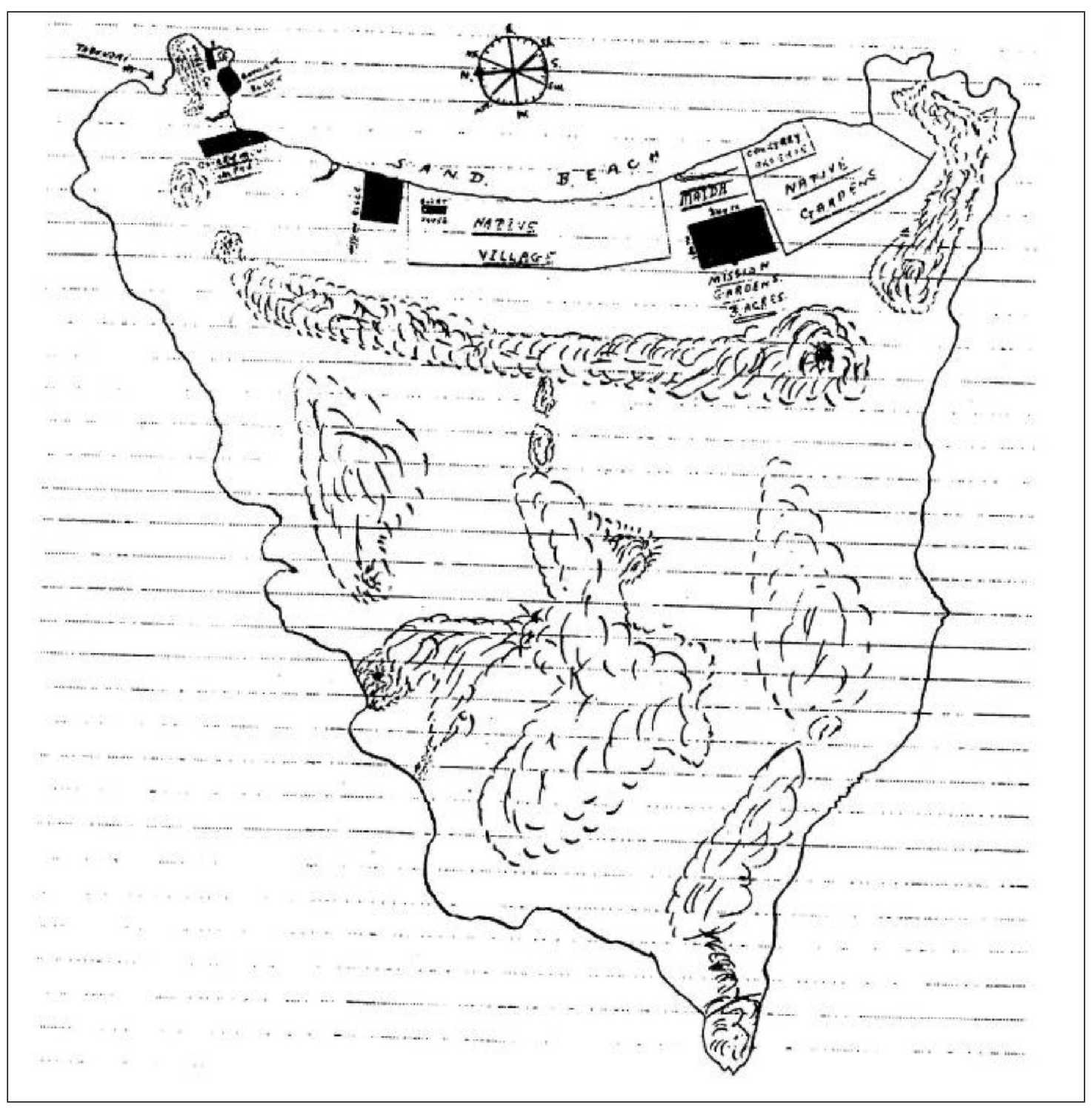

Figure 7. Sketch map of Mabuyag in 1914 (Queensland State Archives file A/58755: Islands, Torres Strait, sketcher unknown. From Eseli et al. 1998:27).

(Barham and Harris 1987:28; Ghaleb 1990, 1998; McNiven and Wright 2008). This is broadly representative of research elsewhere in the Torres Strait, which has a recognised bias towards highly visible, late-Holocene sites (e.g. Barham et al. 2004; David and McNiven 2004). As evidenced by excavations at Wagadagam, such an archaeological approach can ignore early phases of village occupation in the Torres Strait. Archaeological research at Wagadagam identified sub-surface deposits of bone from large vertebrates that date to 1100-550 cal. BP. A similar partnership project at the ethnographically known village of Totalai (on Mua) revealed an antiquity of 1300-1400 cal. BP for the initial phase of village settlement (Ash and David 2008). These excavations reveal the value of partnership archaeology and suggest that the methodology will improve our understanding of late-Holocene settlement in the Torres Strait.

While oral histories may or may not always converge with archaeological remains, this paper suggests that negotiation between indigenous and non-indigenous archaeologists is likely to enable the mutual development of both the prehistoric record and the oral history. Adhi Cygnet Repu (pers. com. Mabuyag, 20/04/2010) identifies the reciprocal role and importance 
of archaeology and ethnography within the cultural heritage process, saying: 'it [archaeology] is useful for us [Goemulgal]. It makes us ask questions about our important villages. There are some points we can ask why the archaeology is not the same as our stories.' Community histories provide archaeologists with an equally distinct (and in some cases) confronting set of questions.

It is recognised that cross-cultural distinctions exist in the classification of 'villages'. Such locations are regarded as both residential areas and the meaningful places connected with community identity (McNiven et al. 2004; David and Ash 2008). However, Maidh is ethnographically known to be a site deliberately restricted from the majority of the Goemulgaw. This was an important socio-political and ceremonial centre, but was not expected to be a residential centre. It is equally clear that Wagadagam (along with all other ethnographically known villages) continues to be conceived by the resident Mabuyag population as a village (in the present rather than past tense) despite the physical relocation of the Goemulgal away from this site at least 150 and possibly 550 years ago. These different ideas about what constitutes a village contribute to a broader understanding of what is 'significant' about these sites. An archaeological perspective is frequently (although not always) grounded in domesticity and utilitarian material culture, while the indigenous conception frequently identifies material culture as secondary to, and a result of, how people look at and organise a social space. Oral histories identify villages to be socio-politically and ceremonially distinct, with individuality often inscribed on to the landscape through totemic markers and monument architecture (Wright In prep). In effect, representing 'conflicting' views of what constitutes a 'village' requires a partnership approach whereby villages are recognised to be unique and the presence/absence of material culture can be viewed as the result of different types of social activity.

Following previous research, this paper highlights a partnership model for negotiating indigenous cultural heritage. While cultural materials and site visibility remain useful methods of site selection, it is important that cultural-heritage practitioners recognise the limitations of this approach. It is also essential that expectations of variation/disagreement between oral and archaeological histories should not result in the avoidance of such sites or situations (EchoHawk 1997; McNiven and Russell 2005:256). While such an approach is liable to highlight divisions between different belief systems, it is important that the value and limitations of each historical perspective are recognised in establishing a cross-cultural working relationship. When discrepancies do exist, these need not be viewed as problematic, but instead an exciting opportunity to develop a deeper mutual understanding of the past.

\section{Acknowledgements}

I thank the Goemulgaw community for its help and support. In particular, Tim Gizu and Edmund Bani, who shared their time and stories with me. Thanks also to AIATSIS for funding the project and the field crew - Beboy Whap, Thomas Whap, Ben Watson, Cameo Daley, Alice Bedingfield, Matt Coller and Sally May. Thanks also to Tim Denham, Jeremy Ash, Ian McNiven, John Bradley, Matt Coller, Pamela Ricardi and Sara Booth for reviewing drafts of this paper. 


\section{References}

Allen, J. 1983. Aborigines and archaeologists in Tasmania. Australian Archaeology 16:7-10.

Ash, J. and David, B. 2008. Mua 22: Archaeology at the old village site of Totalai. In: David, B., Manas, L. and Quinnell, M. (eds), Gelam's homeland: Cultural and natural history of the island of Mua, Torres Strait Volume 4, pp. 451-472. Memoirs of the Queensland Museum Cultural Heritage Series, Brisbane.

Barham, A.J. 2000. Late Holocene maritime societies in the Torres Strait Islands, northern Australia cultural arrival or cultural emergence? In: O'Connor, S. and Veth, P. (eds), East of Wallace's Line: Studies of past and present maritime cultures of the Indo-Pacific Region. Modern Quaternary Research in Southeast Asia 16:223-314.

Barham, A.J. and Harris, D.R. 1987. Final report to the research and exploration committee of the National Geographic Society on the Torres Strait Research Project. Part IIB: July-October 1985. Archaeological and Palaeoenvironmental Investigations in Western Torres Strait, Northern Australia.

Barham, A., Roland, M. and Hitchcock, G. 2004. Torres Strait Bepotaim: An overview of archaeological and ethnoarchaeological investigations and research. In: McNiven, I.J. and Quinnell, M. (eds), Torres Strait archaeology and material culture Volume 3, pp. 1-72. Memoirs of the Queensland Museum Culture Heritage Series, Brisbane.

David, B. and Ash, J. 2008. What do early European contact-period villages in Torres Strait look like? Archaeological implications. In: David, B., Manas, L. and Quinnell, M. (eds), Gelam's homeland: Cultural and natural history of the island of Mua, Torres Strait Volume 4. Memoirs of the Queensland Museum Cultural Heritage Series, Brisbane.

David, B. and McNiven, I.J. 2004. Western Torres Strait cultural history project: Research design and initial results. In: McNiven, I.J. and Quinnell, M. (eds), Torres Strait archaeology and material culture Volume 3, pp. 199-208. Memoirs of the Queensland Museum Culture Heritage Series, Brisbane.

David, B. and Weisler, M. 2006. Kurturniawak (Badu) and the archaeology of villages in Torres Strait. Australian Archaeology 63:21-34.

David, B., McNiven, I.J., Manas, L., Manas, J., Savage, S. and Crouch, J. 2004. Goba of Mua: Archaeology working with oral tradition. Antiquity 78:158-172.

Davis, S.L. and Prescott, J.R.V. 1992. Torres Strait Aboriginal frontiers and barriers in Australia. Melbourne University Press, Melbourne.

Echo-Hawk, R. 1997. Forging a new ancient history for Native America. In: Swindler, N., Dongoske, K.E., Anyon, R. and Downer, A.S. (eds), Native Americans and archaeologists: Stepping stones to common ground. AltaMira Press, Walnut Creek.

Eseli, P., Shnukal, A. and Mitchell, R. 1998. Eseli's notebook. Aboriginal and Torres Strait Islander Studies Unit Research Report Series Volume 3. University of Queensland Press, Brisbane.

Fitzpatrick, J., Cordell, J. and McNiven, I.J. 1998. Torres Strait culture site documentation project. Unpublished report to the Island Co-ordinating Council, Thursday Island, Torres Strait.

Ghaleb, B. 1990. An ethnoarchaeological study of Mabuiag Island, Torres Strait, Northern Australia. Unpublished $\mathrm{PhD}$ thesis, University College London, London.

Ghaleb, B. 1998. Fish and fishing on a Western Torres Strait island, Northern Australia: Ethnographic and archaeological perspectives. In: Jones, A.K.G. and Nicholson, R. (eds), Fish remains and humankind. Volume 2. Internet Archaeology 4.

Haddon, A.C. 1890. The ethnography of the Western Tribe of Torres Straits. The Journal of the Anthropological Institute of Great Britain and Ireland 19:297-440.

Haddon, A.C. 1904. Reports of the Cambridge anthropological expedition to Torres Straits: Sociology, magic and religion of the Western Islanders Volume 5. Cambridge University Press, Cambridge.

Haddon, A.C. 1932. Head-Hunters black, white and brown (2nd edition). Watts and Co, London.

Haddon, A.C. 1935. Reports of the Cambridge anthropological expedition to Torres Straits: General ethnography Volume 1. Cambridge University Press, Cambridge.

Harris, D.R., Barham, A.J. and Ghaleb, B. 1985. Archaeology and recent palaeoenvironmental history of Torres Strait, Northern Australia. Preliminary report to the Research and Exploration Committee of the National Geographic Society on Part IIa of the Torres Strait Research Project, July-October 
1984. Institute of Archaeology, University of London and Department of Geography.

Jukes, J.B. 1847. Narrative of the surveying voyage of the Fly, Commanded by Captain F.P. Blackwood, in

Torres Strait, New Guinea and other islands of the Eastern Archipelago during the years 1842-1846

(Volume 1). T. and W. Boone, London.

Lawrie, M. 1970. Myths and legends of the Torres Strait. University of Queensland Press, Queensland.

Lawrie, M. 1972. Tales from Torres Strait. University Queensland Press, Queensland.

Marshall, Y. 2002. What is community archaeology? World Archaeology 34(1):211-219.

McNiven, I.J. 2006. Dauan 4 and the emergence of ethnographically-known social arrangements across

Torres Strait during the last 600-800 years. Australian Archaeology 62(1):1-13.

McNiven, I.J. and Bedingfield, A. 2008. Past and present marine mammal hunting rates and abundances: Dugong (Dugong dugon) evidence from Dabangai bone mound, Torres Strait. Journal of Archaeological Science 35:505-515.

McNiven, I.J. and Feldman, R. 2003. Ritually orchestrated seascapes: Hunting magic and dugong bone mounds in Torres Strait, NE Australia. Cambridge Archaeological Journal, 13(2):169-194.

McNiven, I.J. and Russell, L. 2005. Appropriated pasts: Indigenous peoples and the colonial culture of archaeology. Altamira Press, Lanham, New York, Toronto, Oxford.

McNiven, I.J. and Wright, D. 2008. Ritualised marine midden formation in Western Zenadh Kes (Torres Strait). In: Clark, G., Leach, F. and O'Connor, S. (eds), Islands of inquiry: Colonisation, searfaring and the archaeology of maritime landscapes, pp. 133-148. Terra Australis 29, ANU EPress, Canberra.

McNiven, I.J., Fitzpatrick, J. and Cordell, J. 2004. An islander world: Managing the archaeological heritage of Torres Strait. In: I.J. McNiven and Quinnell, M. (eds), Torres Strait Archaeology and Matrial Culture Volume 3, pp. 74-91. Memoirs of the Queensland Museum Culture Heritage Series, Brisbane.

McNiven, I.J., David, B., Goemulgaw Kod and Fitzpatrick, J. 2009. The Great Kod of Pulu: Mutual historical emergence of ceremonial sites and social groups, Torres Strait, Northeast Australia. Cambridge Archaeological Journal 19(3):92-108.

Mooke, T. and Simpson, B. 1972. Mabuiag Lag. Unpublished collected stories. Mabuyag Island Council, Mabuyag.

Moore, D. 1984. The Torres Strait collection of A.C. Haddon. British Museum Publishing Ltd, Britain.

Nicholas, G.P. 2000. Indigenous land rights, education, and archaeology in Canada: Postmodern/ postcolonial perspectives by a non-Canadian white guy. In: Lilley, I. (ed), Native Title and the transformation of archaeology in the postcolonial world, pp. 121-137. Oceania Monographs 50. Oceania Publications, Sydney.

Sand, C. 2000. Reconstructing 'traditional' Kanak society in New Caledonia: The role of archaeology in the study of European contact. In: Clarke, A. and Torrence, R. (eds), The archaeology of difference: Negotiating cross-cultural engagements in Oceania, pp. 32-50. Routledge, London.

Shnukal, A.R. 2004. The post-contact created environment in the Torres Strait Central Islands. In: McNiven, I.J. and Quinnell, M. (eds), Torres Strait archaeology and material culture Volume 3, pp. 317-346. Memoirs of the Queensland Museum Culture Heritage Series, Brisbane.

Smith, L. 1999. Decolonizing methodologies: Research and Indigenous peoples. Zed Books Ltd, London and New York.

Smith, C. and Wobst, H.M. 2005. Indigenous archaeologies: Decolonizing theory and practice. One World Archaeology 47, Routledge, Abingdon and New York.

Stevenson, B. 1987. Wings across the sea. Boolarong Publications, Brisbane.

Sutton, P. 1995. Country: Aboriginal boundaries and land ownership in Australia. Aboriginal History Monograph 3, Canberra, Australian National University.

Vanderwal, R. 1973. The Torres Strait: Protohistory and beyond Volume 2. University of Queensland Occasional Papers, Queensland.

Wright, D. 2009. The archaeology of community emergence and development on Mabuyag in the Western Torres Strait. Unpublished PhD thesis, Monash University, Melbourne.

Wright, D. In prep. Approaching community through archaeology on Mabuyag in the Central Western Torres Strait, Northeast Australia. 